\title{
Combination drug therapy for persistent pulmonary hypertension of the newborn
}

\author{
Noritaka Yokoo*, Chieko Marumo, Yoshinobu Nishida, Jun Iio, Shinji Maeda and Toshiro Maihara \\ Department of Pediatrics, Hyogo Prefectural Tsukaguchi Hospital, Japan
}

\section{Introduction}

Persistent pulmonary hypertension of the newborn (PPHN) is one of the most serious neonatal conditions, with an overall mortality rate of $4-33 \%$ [1]. For this condition, inhaled nitric oxide (iNO) and extracorporeal membrane oxygenation (ECMO) have been recognized as effective therapies and can significantly improve survival and reduce morbidity [2,3]. ECMO, however, is a very invasive therapy and can only be administered in limited institutions. On the other hand, various alternative pulmonary vasodilator drugs for PPHN have been reported, such as sildenafil, beraprost, or bosentan [4-6]. We successfully treated a patient with PPHN caused by meconium aspiration syndrome (MAS) with iNO, sildenafil, and bosentan. Here we describe the therapeutic course of this patient and discuss the interaction of pulmonary vasodilators. There are few reports of bosentan administration for patients with PPHN, and this is the first report of a patient experiencing PPHN caused by MAS rescued with combination therapy comprising iNO, sildenafil, and bosentan.

\section{Case report}

A 30-year-old mother delivered a male neonate at 39 weeks of gestation by spontaneous vaginal delivery at the maternity hospital. Cardiotocogram showed fetal variable deceleration, and the amniotic fluid was stained by meconium. The infant's birth weight was 3360 $\mathrm{g}$, and his Apgar scores were 5 and 6 at 1 and $5 \mathrm{~min}$, respectively. He developed MAS and neonatal asphyxia; therefore, he was transferred to our hospital for intensive care. Upon admission to the neonatal intensive care unit (NICU), his $\mathrm{SpO}_{2}$ was 30\%, therefore we immediately intubated the patient. Intratracheal surfactant administration was performed, and mechanical ventilation was started. An echocardiogram revealed that the intraventricular septum (IVS) was flat and the flow through his ductus arteriosus (DA) was shunted right to left, despite deep sedation and catecholamine support (Figure $1 \mathrm{~b}$ and $1 \mathrm{c}$ ). We diagnosed PPHN and administered oxygen at the maximum concentration $\left(\mathrm{FiO}_{2}=1.0\right)$ and began iNO up to $40 \mathrm{ppm}$. His chest $\mathrm{x}$-ray was compatible with MAS (Figure 1a). His pulmonary hypertension $(\mathrm{PH})$ was well controlled under the use of iNO, and we could reduce iNO to $20 \mathrm{ppm}$ by day 2 . We could not, however, reduce iNO below $20 \mathrm{ppm}$ because of recurrent systemic $\mathrm{PH}$ and hypotension caused by $\mathrm{PH}$. We confirmed by echocardiogram on day 2 that his DA was spontaneously closed. To treat his $\mathrm{PH}$, we began sildenafil at 1 $\mathrm{mg} \cdot \mathrm{kg}^{-1} \bullet \mathrm{day}^{-1}$ and doubled this dose after $12 \mathrm{~h}$. After administration of sildenafil, we could gradually reduce the iNO concentration. On day 4, we could reduce the iNO concentration to $2 \mathrm{ppm}$, so we attempted to stop iNO therapy. Soon after stopping iNO, the patient's PH worsened. His blood pressure decreased, and on the echocardiogram, his IVS was flat and his right ventricle was considerably enlarged (Figure 1d).
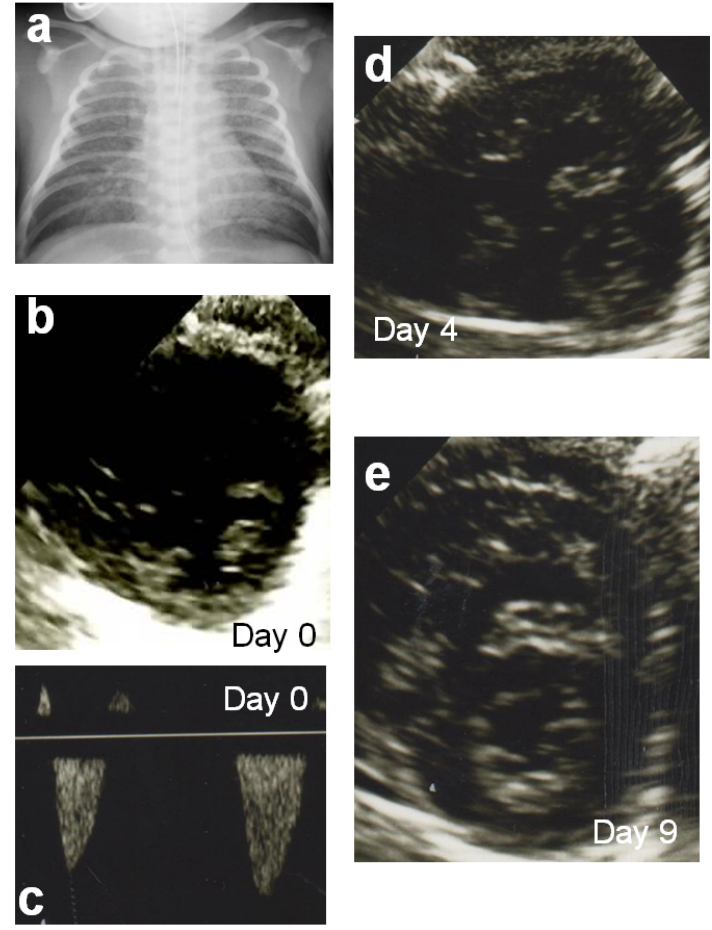

Figure 1. (a) Chest $x$-ray at admission was compatible with meconium aspiration syndrome (MAS). (b,c) Cardioechography at admission. Short axis view revealed flat intraventricular septum (IVS) and ductus arteriosus (DA) flowshunted from right to left because of severe pulmonary hypertension. (d) Cardioechography on day 4 when PH recurred because of discontinuing inhaled nitric oxide (iNO); IVS was flat and the right ventricle (RV) was remarkably enlarged because of severe PH. (e) Cardioechography on day 9 when iNO was successfully discontinued; the IVS was round, and dilatation of the RV was improved.

We were forced to resume iNO at $3 \mathrm{ppm}$. Only at a concentration of 3 ppm was iNO effective, and the patient's $\mathrm{PH}$ was well-controlled. To wean the neonate off iNO, sildenafil was escalated to $2 \mathrm{mg} \cdot \mathrm{kg}^{-1} \bullet \mathrm{day}^{-1}$. Bosentan administration was started at $1 \mathrm{mg} \cdot \mathrm{kg}^{-1} \cdot \mathrm{day}^{-1}$ and doubled after $12 \mathrm{~h}$, which was the initial dose. On day 6 we attempted to stop iNO administration once more, but again $\mathrm{PH}$ was recurrent. We next titrated the dose of bosentan up to $2 \mathrm{mg} \cdot \mathrm{kg}^{-1} \bullet \mathrm{day}^{-1}$ on day 6 , after which,

Correspondence to: Noritaka Yokoo, Department of Pediatrics, Hyogo Prefectural Tsukaguchi Hospital, Japan, Tel: +816-6429-5321; Fax: +816-64227405; E-mail: n_yokoo@f7.dion.ne.jp

Key words: persistent pulmonary hypertension of the newborn, inhaled nitric oxide, sildenafil, bosentan

Received: July 14, 2017; Accepted: August 21, 2017; Published: August 24, 2017 
his $\mathrm{PH}$ improved remarkably. $\mathrm{His} \mathrm{SpO}_{2}$ became more stable with lowered $\mathrm{FiO}_{2}$ (up to 0.5 ), and iNO could also reduced to $1 \mathrm{ppm}$. On day 9, we were able to wean the patient off iNO therapy (Figure 2). Sildenafil and bosentan were also discontinued on days 17 and 15, respectively. The patient was extubated on day 20, and he was discharged on day 48 with no medication for $\mathrm{PH}$, including oxygen therapy. When we used iNO, sildenafil, and bosentan, we fully informed his parents about effects of the drug and potential adverse effects, and informed consent was obtained. However, no adverse effects of sildenafil or bosentan were observed.

\section{Discussion}

The nitric oxide (NO) pathway involves the production of cyclic guanosine monophosphate (cGMP) in vascular smooth muscle cells, subsequently activating cGMP kinase through calcium channel inhibition. A decrease in calcium entry and calcium release from sarcoplasmic stores diminishes activation of the contractile apparatus and leads to vasodilatation [7] (Figure 3). In MAS, some pulmonary alveoli do not contribute gas exchange because of small atelectasis, resulting in ventilation-perfusion imbalance. However, iNO acts in intact pulmonary alveoli resulting in dilation of pulmonary vessels that only contribute to gas exchange. Therefore, iNO therapy corrects the ventilation-perfusion imbalance caused by MAS. Sildenafil, which is a highly specific PDE5 inhibitor, prevents breakdown of cGMP and regulates cGMP levels in vascular smooth muscle cells [8] (Figure 3).

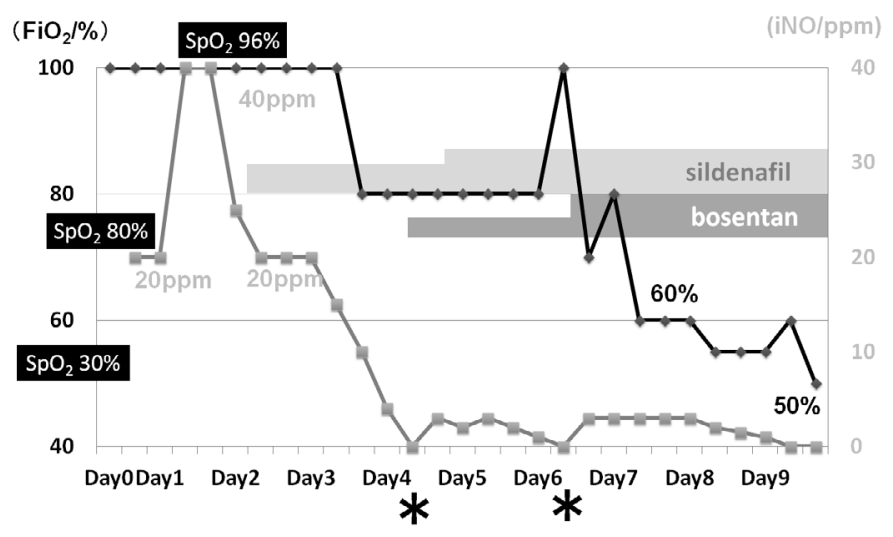

Figure 2. Clinical course: $(\checkmark)$ concentration of oxygen $\left(\mathrm{FiO}_{2}\right)$; $(\boldsymbol{\bullet})$ concentration of inhaled nitric oxide (iNO). Asterisk shows recurrence of pulmonary hypertension $(\mathrm{PH})$.

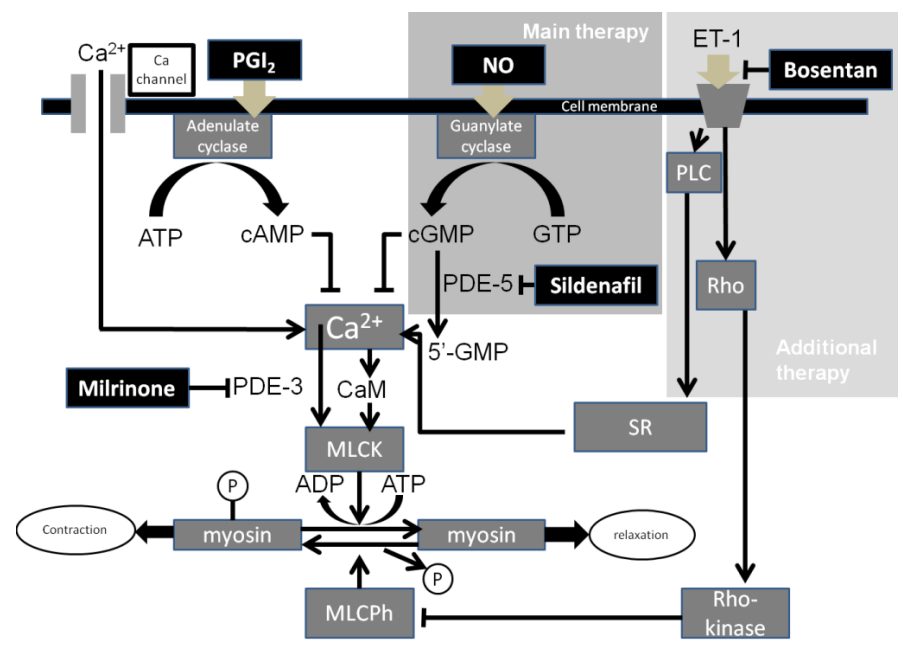

Figure 3. Cellular mechanisms of pulmonary vasodilators and their interaction.
Hypotension caused by the coadministration of oral nitrate and sildenafil was previously described [9]. It is suggested that combination therapy with iNO and sildenafil leads to a synergistic effect for pulmonary vasodilation, because under conditions of elevated cGMP concentration, sildenafil acts as a more powerful vasodilator by preventing breakdown of the high concentration of cGMP. In our case, sildenafil was very effective at low doses during inhalation of NO, probably because the interaction between iNO and sildenafil acted as a more powerful vasodilator by the abovementioned mechanism. But when we weaned the patient off iNO, sildenafil was less effective than under the condition of iNO administration. Because the cGMP level was low, a limited effect of sildenafil administration was expected. A pulmonary vasodilator that acts through a different mechanism was needed. We used bosentan-an endothelin-1 (ET-1) receptor antagonist and pulmonary vasodilator-as an additional therapy for $\mathrm{PH}[10]$. Because, bosentan is not affected by the iNO pathway, after iNO was stopped, bosentan acted well as a pulmonary vasodilator, with its action similar to that under the administration of iNO. We therefore successfully weaned the patient off iNO (Figure 3).

In conclusion, we successfully treated a patient with PPHN caused by MAS by using combination therapy comprising iNO, sildenafil, and bosentan. Pulmonary vasodilators should be selected on the basis of their underlying mechanisms of action.

\section{References}

1. Walsh-Sukys MC, Tyson JE, Wright LL, Bauer CR, Korones SB, et al. (2000) Persistent pulmonary hypertension of the newborn in the era before nitric oxide: practice variation and outcomes. Pediatrics 105: 14-20. [Crossref]

2. Finer NN, Barrington KJ (2006) Nitric oxide for respiratory failure in infants born at or near term. Cochrane Database Syst Rev. [Crossref]

3. Sadiq HF, Mantych G, Benawra RS, Devaskar UP, Hocker JR (2003) Inhaled nitric oxide in the treatment of moderate persistent pulmonary hypertension of the newborn: a randomized controlled, multicenter trial. J Perinatol 23: 98-103.

4. Shah PS, Ohlsson A (2011) Sildenafil for pulmonary hypertension in neonates. Cochrane Database Syst Rev 10: CD005494.

5. Nakwan N, Nakwan N, Wannaro J (2011) Persistent pulmonary hypertension of the newborn successfully treated with beraprost sodium: a retrospective chart review. Neonatology 99: 32-37. [Crossref]

6. Radicioni M, Bruni A, Camerini P (2011) Combination therapy for life-threatening pulmonary hypertension in a premature infant: first report on bosentan use. Eur $J$ Pediatr 170: 1075-1078.

7. Francis SH, Busch JL, Corbin JD, Sibley D (2010) cGMP-dependent protein kinases and cGMP phosphodiesterases in nitric oxide and cGMP action. Pharmacol Rev 62 : 525-563. [Crossref]

8. Archer SL, Michelakis ED (2009) Phosphodiesterase type 5 inhibitors for pulmonary arterial hypertension. $N$ Engl J Med 361: 1864-1871. [Crossref]

9. Webb DJ, Muirhead GJ, Wulff M, Sutton JA, Levi R, et al. (2000) Sildenafil citrate potentiates the hypotensive effects of nitric oxide donor drugs in male patients with stable angina. $J$ Am Coll Cardiol 36: 25-31.

10. Kirkby NS, Hadoke PW, Bagnall AJ, Webb DJ (2008) The endothelin system as a therapeutic target in cardiovascular disease: great expectations or bleak house? $\mathrm{Br} J$ Pharmacol 153: 1105-1119. [Crossref]

Copyright: (C2017 Yokoo N. This is an open-access article distributed under the terms of the Creative Commons Attribution License, which permits unrestricted use, distribution, and reproduction in any medium, provided the original author and source are credited. 